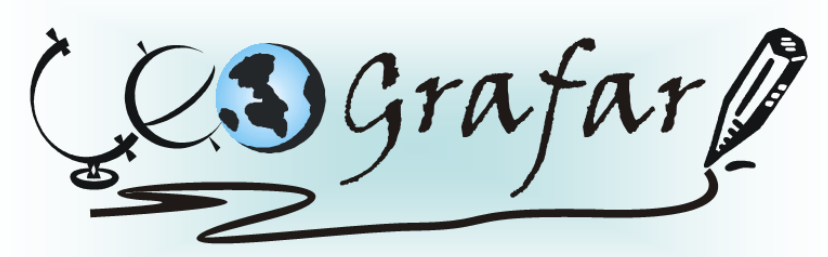

Revista Eletrônica do Programa de Pós-Graduação em Geografia - UFPR

\title{
INCLUSÃO DIGITAL EM TELECENTROS E LAN HOUSES: AS NOVAS DINÂMICAS ESPACIAIS DECORRENTES DOS CENTROS PÚBLICOS DE ACESSO À INTERNET NA PERIFERIA DE PORTO ALEGRE/RS ${ }^{1}$
}

\author{
FERNANDO DREISSIG DE MORAES ${ }^{2}$ \\ PAULO ROBERTO RODRIGUES SOARES ${ }^{3}$
}

\begin{abstract}
RESUMO
A Internet tem proporcionado uma quantidade significativa de transformações na sociedade e, conseqüentemente, no espaço geográfico. No presente trabalho, procuramos enfocar nossa análise na nova forma de exclusão social decorrente da falta ou da precariedade no acesso à Internet: a exclusão digital. Ao mesmo tempo, analisamos se efetivamente ocorre o processo de inclusão digital nos centros públicos de acesso à Internet e quais são as dinâmicas que emergem a partir desses locais, tomando, como recorte espacial, o município de Porto Alegre, principalmente a regiões Norte e Eixo Baltazar. Essa pesquisa demonstrou um panorama atual dos impactos das Tecnologias de Informação e Comunicação e como as mesmas alteram algumas dinâmicas espaciais. Esses centros, sejam eles gratuitos ou pagos, atendem principalmente às camadas da população que não possuem pleno ingresso ao uso de computadores. Os dados obtidos na pesquisa demonstram que, embora haja uma diferença em termos de perfil socioeconômico entre usuários de centros de acesso, existem muitas semelhanças nos usos e na importância adquirida pela Internet para os mesmos. Ao mesmo tempo, foi possível constatar que os centros públicos representam apenas uma entre outras possibilidades de entrada, fato que evidencia uma maior facilidade de obter acesso à Internet atualmente, mesmo que a posse de um computador ainda esteja restrita a uma minoria da população brasileira. As políticas públicas de inclusão digital continuam sendo importantes para o aumento da acessibilidade.
\end{abstract}

Palavras-chave: Centros públicos de acesso à Internet, Inclusão Digital, Internet. Ciberespaço, Porto Alegre.

\footnotetext{
${ }^{1}$ Este artigo é originado a partir das reflexões desenvolvidas em Trabalho de Conclusão de Curso do primeiro autor, apresentado em dezembro de 2009 na Universidade Federal do Rio Grande do Sul (UFRGS) como requisito parcial para a obtenção do grau de Geógrafo.

${ }^{2}$ Licenciado e Bacharel em Geografia. Mestrando no Programa de Pós-Graduação em Geografia (Análise Territorial) - UFRGS.

${ }_{3}^{3}$ Professor Doutor do Departamento de Geografia e do Programa de Pós-Graduação em Geografia UFRGS. Orientador do trabalho.
} 


\title{
DIGITAL INCLUSION IN TELECENTRES AND LAN HOUSES: NEW SPACIAL DYNAMICS DUE TO THE PUBLIC INTERNET ACCESS POINTS ON PERIPHERY OF PORTO ALEGRE/RS
}

\begin{abstract}
Internet has provided a significant amount of changes in society and, consequently, in the geographic space. In this paper, we focus our analysis on the new form of social exclusion resulting from lack or poor access to the Internet: the digital divide. At the same time, we analyzed if the process of digital inclusion are really happening, and what are the dynamics that emerge from these locations, taking as public Internet access points in the North and Eixo Baltazar regions of the city of Porto Alegre. This research verified a current overview of the impacts of Information and Communication Technologies and how they change some spatial dynamics. These centers, whether free or paid, are serving primary to the population's sectors that not have a complete access to the computers. The data obtained in this research show us that there are many likeness in the uses as well as in the importance level of the Internet for the users of access centers, although there is a difference in the socioeconomic profile of them. At the same time, it was identified that public points are just one option between another routes of entry, a fact which shows a greater ease of obtaining Internet access today, although the ownership of a computer are still limited to a small segment of the population. Public policies of digital inclusion are still important to increase accessibility.
\end{abstract}

Keywords: Public Internet access points, Digital Inclusion, Internet, Cyberspace, Porto Alegre.

\section{INTRODUÇÃO}

Contemporaneamente, a Internet possui um papel extremamente importante sob o ponto de vista das relações sociais, culturais, econômicas e comerciais, implicando em transformações inevitáveis no espaço geográfico. De fato, essa rede representa uma maior facilidade para a integração entre diferentes locais, ou seja, incrementa-se a possibilidade de interconexão entre distintas escalas, seja em âmbito local, regional ou global. Entretanto, nota-se que o acesso às plataformas de entrada à Internet (tal como os microcomputadores) ainda é bastante limitado, apesar do crescimento significativo do número de usuários de Internet nos últimos anos. Diante desse cenário, emerge uma nova forma de segregação e exclusão social: a digital. A exclusão digital consiste, portanto, em uma nova barreira socioeconômica promovida pela inacessibilidade às Tecnologias de Informação e 
Comunicação (TICs) e ao ciberespaço (o espaço virtual representado pelo uso destas novas tecnologias, principalmente aquelas conectadas a redes, como a Internet).

No Brasil, apesar de haver um aumento relativo no número de usuários de Internet, o acesso, de maneira geral, ainda se mostra bastante restritivo quanto ao uso dessas ferramentas. Conforme dados da TIC Domicílios ${ }^{4}$, realizada pelo Centro de Estudos sobre as Tecnologias da Informação e da Comunicação (vinculado ao Comitê Gestor da Internet no Brasil) em 2008, 61\% da população brasileira nunca teve acesso à Internet.

Dentro deste contexto, surgem ações que possibilitam, por diferentes modos e objetivos, minimizar essa desigualdade, tanto por promoção do poder público (através de políticas de inclusão digital) quanto por parte da iniciativa privada (visando principalmente o lucro, mas que acaba oferecendo uma possibilidade relativamente barata para o indivíduo utilizar as Tecnologias de Informação e Comunicação) e de organizações não-governamentais (ONGs). Dentro das perspectivas propostas neste artigo, analisam-se dois distintos tipos de locais, constituindo-se no que denominaremos "centros públicos de acesso à Internet": os telecentros e as lan houses.

O objetivo deste artigo consiste em analisar as novas dinâmicas espaciais decorrentes dos centros públicos de acesso à Internet sob a óptica do processo de inclusão digital. Entre os objetivos específicos, busca-se debater as noções de ciberespaço e inclusão/exclusão digital pelo viés da Geografia e de outras ciências sociais; elaborar um histórico de implantação dos centros públicos de acesso à Internet em Porto Alegre; avaliar o modo como vem ocorrendo o processo de inclusão digital nos telecentros e nas lan houses; e, por fim, analisar as particularidades dos diferentes tipos de centros públicos em relação ao perfil do usuário, movimentação de pessoas, infra-estrutura dos estabelecimentos e padrões de usos das TICs a partir de um recorte amostral em Porto Alegre / RS, buscando,

\footnotetext{
${ }^{4}$ A TIC Domicílios 2008 mediu o acesso às Tecnologias da Informação e da Comunicação, uso do computador, uso da Internet, segurança na rede, uso do e-mail, spam, governo eletrônico, comércio eletrônico, habilidades na Internet e acesso sem fio (uso do celular). Como a última pesquisa realizada pelo Instituto Brasileiro de Geografia e Estatística sobre uso de computadores e internet, até a época da pesquisa, era a PNAD de 2005, optou-se por utilizar os dados da referida pesquisa organizada pelo Centro de Estudos sobre as Tecnologias da Informação e da Comunicação, que está disponível em <http://www.cetic.br/>. Acesso em 7 de maio de 2009.
} 
deste modo, estabelecer as diferenças e similitudes inerentes a esses dois âmbitos de acesso público à Internet.

O recorte espacial do estudo é o município de Porto Alegre, mais especificamente a Região Norte e a Região Eixo Baltazar, nos bairros Sarandi, Rubem Berta e Passo das Pedras ${ }^{5}$ (FIGURA 1), como um caso a ser analisado em decorrência da implementação de políticas públicas por parte da Prefeitura Municipal no sentido de promover o acesso à Internet para grupos populacionais total ou parcialmente excluídos do acesso à rede e também em função da grande profusão de lan houses nos últimos anos, fenômeno também observado em outros bairros periféricos de Porto Alegre. A partir disso, considerar-se-á esses dois casos sob a óptica da Geografia, objetivando analisar as transformações espaciais resultantes dos centros públicos de acesso à Internet.

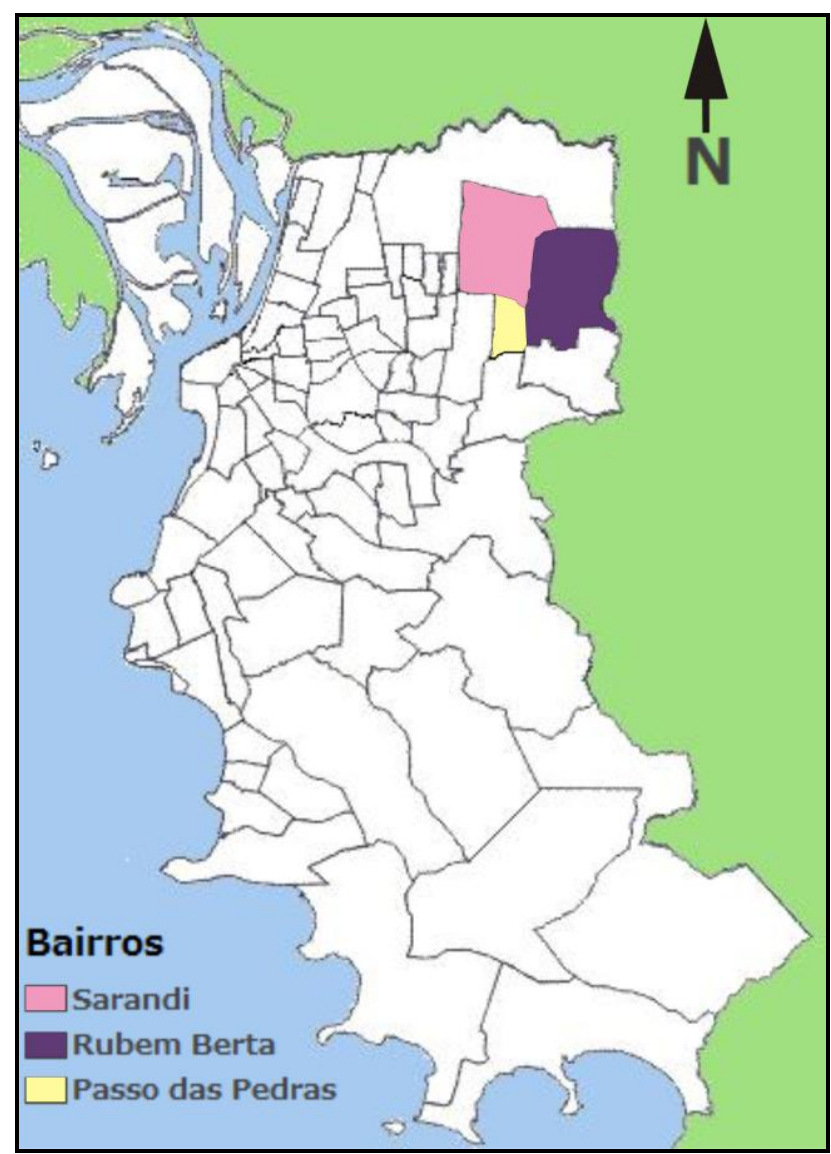

FIGURA 1 - LOCALIZAÇÃO DA ÁREA DO ESTUDO NO MUNICÍPIO DE PORTO ALEGRE

ORGANIZAÇÃO: O autor (2010)

\footnotetext{
${ }^{5} \mathrm{O}$ critério utilizado para essa definição baseia-se na divisão regional do Orçamento Participativo, conforme o Mapa Oficial Digital de Porto Alegre. Disponível em: <http://geo.procempa.com.br/geo/>. Acesso em 10 de junho de 2009.
} 


\section{PROCEDIMENTOS METODOLÓGICOS}

Inicialmente, realizou-se uma revisão bibliográfica visando à construção do referencial teórico que legitimasse os conceitos utilizados no trabalho, tendo como foco a discussão sobre ciberespaço, segregação/exclusão digital, bem como sobre alternativas que minimizem os efeitos implicados por esse fenômeno segregacionista e excludente. Juntamente com isso, elaborou-se esta pesquisa conceitual visando elucidar a problemática na área de estudo, fato que pode contribuir para a continuidade de trabalhos geográficos e de áreas afins acerca do tema.

Em um segundo momento, realizou-se a busca por dados secundários. Essa etapa permitiu uma melhor compreensão da realidade da área de estudo (no caso, o município de Porto Alegre), visando posteriormente o enfoque nas regiões Norte e Eixo Baltazar. A partir disso, foi possível conhecer a quantidade de telecentros existentes em Porto Alegre, bem como a localização dos mesmos, assim como uma estimativa das lan houses localizadas na área estudada. A busca destes dados foi feita através das seguintes fontes: site da Secretaria Municipal de Direitos Humanos e Segurança Urbana de Porto Alegre (SMDHSU); site do projeto dos telecentros, ligado ao portal da Prefeitura Municipal; e consulta de alvarás cadastrados na Secretaria Municipal da Produção, Indústria e Comércio (SMIC) de Porto Alegre. Também foi realizada uma pesquisa documental na própria SMDHSU com o objetivo de buscar o projeto inicial da instalação dos telecentros, ao mesmo tempo em que foi destacada a perspectiva histórica das 38 unidades existentes no período em que foi realizado o presente estudo.

Para a etapa de campo, foram aplicados 20 questionários em usuários de telecentros e lan houses (10 questionários em cada tipo de centro), e realizadas 5 entrevistas com diferentes atores envolvidos no problema de pesquisa (proprietários de lan houses, monitores e gestores de telecentros). Sob posse dos questionários, procurou-se, em linhas gerais, conhecer o perfil dos frequentadores e seus usos em caráter qualitativo e quantitativo. As entrevistas, por sua vez, procuraram não se limitar apenas ao caráter hermético de uma enorme sequência de perguntas. Pretendeu-se, na verdade, valorizar o relato dos entrevistados, não abdicando, contudo, de perguntas que assumissem o papel de eixos norteadores, bem como 
aquelas mais pontuais que buscam reconhecer a finalidade do uso dos microcomputadores naqueles locais e o processo de inserção no ciberespaço.

\section{CONSIDERAÇÕES TEÓRICAS SOBRE O PROBLEMA E O OBJETO DE ESTUDO}

Uma noção extremamente relevante para o tratamento da discussão acerca das redes informacionais é aquela que trata do ciberespaço. Lévy (1999, p. 92) define o ciberespaço como "o espaço de comunicação aberto pela interconexão mundial dos computadores e das memórias dos computadores". Outra contribuição para a definição de ciberespaço vem de Silva e Tancmán (1999, p. 56), na qual os autores o definem como "uma dimensão da sociedade em rede, onde os fluxos definem novas formas de relações sociais".

A partir de uma ideia inicial, a Internet é um meio que propicia contato e relacionamento de modo muito mais facilitado e rápido em comparação com outros meios de comunicação. Historicamente, a partir da criação de novos mecanismos de comunicação em massa, formaram-se grupos excluídos do processo de obtenção do acesso, como foi o caso do surgimento da televisão, do rádio, como lembra Lévy (1999). A Internet não foge a essa tendência. O meio técnico-científicoinformacional, conforme Santos (1994), tende a se superpor a todos os lugares no espaço geográfico de maneira diferenciada. Considera-se, portanto, que existem discrepâncias conforme o poder de penetração dessas novas tecnologias.

O termo "exclusão digital" deriva-se do inglês "digital divide" e está relacionado às barreiras que não permitem o acesso ou tratamento das pessoas às tecnologias de informação, seja em função da falta de oportunidade ou pela falta de conhecimento sobre uso das TICs (LUCAS, 2002, p. 161) . A mesma autora ainda define mais especificamente o termo:

Por exclusão digital entende-se o surgimento de mais uma barreira socioeconômica entre indivíduos, famílias, empresas e regiões geográficas, a qual decorre tanto da desigualdade quanto ao acesso e uso das tecnologias da informação e comunicação, hoje simbolizadas na Internet (LUCAS, 2002, p.161). 
A exclusão digital consiste, portanto, no retrato fidedigno da desigualdade relacionada ao acesso ao ciberespaço representado pela Internet. Embora, historicamente, a criação de novos sistemas de comunicação tenha provocado a formação de grupos excluídos, o não-acesso às TICs representa uma situação ainda mais grave se comparada a outros momentos da história devido ao papel assumido pela Internet na sociedade contemporânea. Como observa Manuel Castells, "a diferenciação entre os que têm e os que não têm Internet acrescenta uma divisão essencial às fontes já existentes de desigualdade e exclusão social" (CASTELLS, 2003, p. 203).

Visto que ainda há uma série de fatores impeditivos para obter o pleno acesso ao ciberespaço, surgem ações que buscam minimizar o problema da exclusão digital. Em curto prazo, faz-se necessária a criação de políticas públicas para promoção da inclusão digital, tanto em escala nacional (em programas fomentados pelo Governo Federal), como em escala local (através de programas e ações implementadas pelos municípios). Neste sentido, os telecentros comunitários apresentam-se como uma alternativa viável para proporcionar o acesso à Internet para aqueles que não o possuem plenamente, seja devido a limitações financeiras ou à falta de treinamento e habilidade com as novas tecnologias, inclusive para parcelas da população que jamais estiveram inseridas no ciberespaço. Como lembra Chaparro (2007), os telecentros são considerados uma alternativa para diminuir as distâncias relacionadas à segregação sócio-digital, ao promover alternativas de inclusão para aqueles cujo acesso é escasso. Ueda sistematiza os objetivos da implantação dos telecentros:

A través de la Internet, las iniciativas locales se integran a una red global, posibilitando un nuevo tipo de actividad económica e política, centrada en múltiplas localidades conectadas digitalmente. Es en ese contexto que los telecentros son importantes, pues son espacios que la población tiene disponible las tecnologías de la información y pueden ascender a la sociedad de la información. Ellos tendrán derechos y oportunidades de aprender y utilizar las tecnologías. Superando los limites entre el equipamiento (el ordenador) y la apropiación del mismo, dando oportunidades a que los ciudadanos mejoren sus condiciones de vida y estimulen a la democratización de la información en un sentido más solidario. Haciendo que la ciudad tenga espacios colectivos y que los ciudadanos luchen por una sociedad mas justo y un otro mundo posible para todos, promoviendo la inclusión de social a través de la inclusión digital. (UEDA, 2004). 
Portanto, os telecentros apresentam, em resumo, o objetivo de oferecer acesso às TICs para parcelas da população que não teriam condições de ingressar ao ciberespaço, principalmente aquelas em áreas periféricas sócio-espacialmente excluídas. Conforme Sorj (2003), esses se constituem no principal e mais rápido instrumento de políticas de acesso à Internet em países em desenvolvimento.

Todavia, o cenário atual, ao menos no Brasil, ainda não se mostra tão favorável quando se considera a ampliação e a magnitude das políticas de inclusão digital. Assumpção (2001) define "inclusão digital" como:

(...) os esforços de fazer que as populações das sociedades contemporâneas possam obter os conhecimentos necessários para utilizar linguagens e capacidades dos recursos de TICs existentes e possam dispor de acesso regular aos equipamentos que possibilitam a existência destas tecnologias (ASSUMPÇÃO, 2001, p. 12).

Essa inclusão, no entanto, se dá de diferentes maneiras e intensidades; varia, por exemplo, desde o simples manuseio do computador até a utilização da Internet para produção de conhecimento ou para participação popular na decisão de projetos do Governo (a chamada "democracia eletrônica"). Não tentaremos fazer uma distinção mais aprofundada entre essas peculiaridades neste trabalho, mas procuraremos identificar os diferentes usos - se eles existirem - entre usuários de lan houses e telecentros.

Com exceção de alguns casos isolados, os municípios brasileiros ainda se apresentam em um estágio distante de uma efetiva inclusão de todos os seus moradores nas TICs. Em regiões com menores índices de renda e, por conseguinte, de posse de microcomputadores, nas quais a demanda por centros públicos é maior, a pouca expressividade de telecentros provoca um aumento da quantidade de centros de acesso pago, tal como os cybercafés e as lan houses. Neste estudo, porém, serão priorizadas as últimas. Essa escolha se deve à percepção de que são as lan houses que vem se proliferando nos bairros mais pobres das grandes metrópoles (ao menos esse é o termo mais comum nas fachadas destes empreendimentos localizados nessas áreas) "preenchendo" a ausência dos telecentros em sua função social de possibilitar o acesso à Internet. 


\section{INTERNET NO BRASIL E A ATUAÇÃO DAS ESFERAS PÚBLICA E PRIVADA}

Nesta seção, analisa-se sob dois pontos de vista a questão da inclusão digital: primeiramente, a partir da figura estatal como promotora de políticas públicas, enfatizando os telecentros comunitários; em um segundo momento, essa análise será aprofundada com as lan houses, ramo da iniciativa privada que se consolida a partir da pouca eficiência dessas políticas públicas de inclusão digital, inclusive nas grandes cidades.

\subsection{INCLUSÃO DIGITAL, ESTADO E TELECENTROS}

As políticas públicas de inclusão digital, atualmente, já constituem um elemento importante no contexto da gestão territorial do Estado, que deve ser considerado na pauta dos programas sociais em âmbito federal, estadual e municipal. A figura estatal constitui-se em um dos principais agentes produtores do espaço, por meio de suas políticas territoriais. Pode-se depreender, portanto, a posição privilegiada desse ator sob o ponto de vista do planejamento e da execução de ações visando à democratização do acesso à Internet. No contexto da descentralização, da participação social e da sustentabilidade do desenvolvimento estatal, essa tendência pode ser percebida em muitas das iniciativas atuais de inclusão digital, nas quais a figura da sociedade civil ganha um papel importante na participação executiva de muitos projetos, como é o caso do Programa de Telecentros do município de Porto Alegre, através da parceria estabelecida entre Estado e organizações comunitárias (principalmente associações de bairro) ou ONGs.

O Programa Computador para Todos, através da redução de impostos, vem estimulando a compra desse equipamento entre as camadas mais pobres da população. Contudo, apenas a redução do preço não cessa o problema, já que os custos para a manutenção da Internet ainda são altamente onerosos para muitas famílias e, em certos locais, a infra-estrutura básica para a instalação de Internet ainda inexiste, até mesmo em alguns importantes centros urbanos brasileiros. Em escala nacional, o desafio de uma política de inclusão digital não é dificultado 
apenas pela extensão do território e pelas especificidades regionais brasileiras, mas pela necessidade de investimento em áreas essenciais, como na educação. Essa é um pré-requisito fundamental para um bom uso das inovações das TICs, principalmente quanto a seu potencial como mecanismo para a democracia eletrônica e para a sua utilização no ensino formal.

Embora apresente avanços nos últimos anos, o cenário atual ainda está bastante distante da idealizada universalização do acesso. Entre os problemas estruturais, destacamos, com base nos dados obtidos na pesquisa de Afonso (2007), os seguintes: indisponibilidade de estruturas mais avançadas de telecomunicações e Internet em $44 \%$ dos municípios brasileiros; baixa qualidade de conexão (principalmente no espaço rural); quantidade significativa de bairros que não dispõem de serviços de banda larga; baixa quantidade de computadores públicos gratuitos (como telecentros, bibliotecas ou escolas públicas); e, por fim, falta de condições financeiras de uma parte das famílias brasileiras.

Entretanto, sem sombra de dúvida, umas das alternativas que mais vem obtendo êxito visando à redução da inacessibilidade às TICs são os telecentros, mesmo que, em termos quantitativos, ainda haja um significativo déficit no Brasil. A origem de centros públicos para o uso das TICs remonta ao final da década de 70. O conceito de "experiências sociais com Novas Tecnologias de Informação" foi criado na França, em 1978, em um contexto de aumento do uso da informática pela sociedade civil. Porém, foi a partir da década de 80 , com os Centros de Informação e de Serviços da Comunidade (CISC) nos países escandinavos, que o atual modelo de telecentros começou a tomar forma, como um local em que se instalam aparelhos de TICs à disposição dos cidadãos de comunidades periféricas, com o objetivo de dar um uso comum e público às instalações disponíveis.

As políticas públicas de universalização do acesso à Internet, entretanto, ainda não apresentam uma significativa representatividade em muitas áreas que necessitam de melhores índices de acessibilidade, inclusive em cidades como Porto Alegre. O desenvolvimento dos telecentros constitui-se, ao menos nos próximos anos, como uma das medidas mais eficazes visando à redução da exclusão digital. Esse objetivo, entretanto, só poderá ser cumprido a partir da instituição de políticas públicas efetivamente voltadas ao combate desse viés de desigualdade. Enquanto essa iniciativa não é acessível à grande parte da população, emerge, a partir da 
iniciativa privada, um tipo de serviço pago voltado àqueles que não têm acesso regular à Internet: as lan houses. Um crescimento expressivo no número de estabelecimentos deste caráter vem sendo observado nos últimos anos, principalmente em regiões periféricas não atendidas (ou atendidas de modo deficitário) por políticas públicas de inclusão digital. Conforme a tabela 1 , os telecentros representam para apenas $1 \%$ da população o local mais frequente de acesso à Internet, em contraposição com os centros pagos, com $35 \%$ (ficando somente atrás do acesso residencial no panorama geral nacional, mas sendo superior nas regiões Norte e Nordeste).

TABELA 1 - LOCAL DE ACESSO INDIVIDUAL À INTERNET - MAIS FREQUENTE BRASIL

\begin{tabular}{|c|c|c|c|c|c|c|c|}
\hline \multicolumn{2}{|l|}{ Percentual (\%) } & $\begin{array}{l}\text { Em } \\
\text { casa }\end{array}$ & $\begin{array}{l}\text { Centro } \\
\text { público } \\
\text { de } \\
\text { acesso } \\
\text { pago }\end{array}$ & $\begin{array}{l}\text { No } \\
\text { trabalho }\end{array}$ & $\begin{array}{l}\text { Na casa } \\
\text { de } \\
\text { outra } \\
\text { pessoa }\end{array}$ & $\begin{array}{l}\mathrm{Na} \\
\text { escola }\end{array}$ & $\begin{array}{l}\text { Centro } \\
\text { público } \\
\text { de } \\
\text { acesso } \\
\text { gratuito }\end{array}$ \\
\hline \multicolumn{2}{|c|}{ TOTAL ÁREA URBANA } & 36 & 35 & 14 & 9 & 5 & 1 \\
\hline \multirow[t]{5}{*}{ REGIÖES DO PAÍS } & SUDESTE & 41 & 30 & 14 & 9 & 5 & 1 \\
\hline & NORDESTE & 22 & 54 & 8 & 9 & 4 & 2 \\
\hline & SUL & 41 & 23 & 19 & 10 & 6 & 1 \\
\hline & NORTE & 20 & 52 & 11 & 8 & 8 & 1 \\
\hline & CENTRO-OESTE & 37 & 28 & 18 & 11 & 5 & 1 \\
\hline \multirow[t]{6}{*}{ RENDA FAMILIAR } & Até $\mathrm{R} \$ 415$ & 7 & 75 & 2 & 7 & 6 & 3 \\
\hline & $\mathrm{R} \$ 416-\mathrm{R} \$ 830$ & 14 & 57 & 5 & 14 & 8 & 2 \\
\hline & $\mathrm{R} \$ 831-\mathrm{R} \$ 1245$ & 30 & 42 & 12 & 9 & 6 & 1 \\
\hline & $\mathrm{R} \$ 1246-\mathrm{R} \$ 2075$ & 45 & 24 & 19 & 8 & 4 & \\
\hline & $\mathrm{R} \$ 2076-\mathrm{R} \$ 4150$ & 58 & 11 & 20 & 7 & 2 & 1 \\
\hline & $\mathrm{R} \$ 4151$ ou mais & 63 & 5 & 28 & 3 & 1 & - \\
\hline
\end{tabular}

FONTE: COMITÊ GESTOR DA INTERNET NO BRASIL - CGI.BR (2008) ADAPTADO PELO AUTOR.

\subsection{LAN HOUSES: A EMERGÊNCIA DE UM RAMO DA INICIATIVA PRIVADA NO HIATO DE POLÍTICAS PÚBLICAS DE INCLUSÃO DIGITAL}

As lan houses caracterizam-se como estabelecimentos comerciais que oferecem, em sua grande maioria, dois tipos de serviços: acesso à Internet e jogos eletrônicos. Dentro dos objetivos deste trabalho, contudo, delimita-se a dimensão destes estabelecimentos apenas quanto ao acesso à Internet devido à intenção de analisar os telecentros e as lan houses sob a perspectiva da inclusão digital e das transformações socioespaciais. 
As lan houses, em definição, são locais dotados de computadores conectados em rede que proporcionam acesso à Internet e jogos. Além disso, alguns desses estabelecimentos também oferecem outros tipos de serviços, como impressão, scanner, consultas na web (como comprovantes de quitação eleitoral e atestados de bons antecedentes). Algumas vão mais além, oferecendo também manutenção e conserto de máquinas, instalação de programas e redes, entre outros.

A importância destes empreendimentos no contexto brasileiro de acesso à Internet vem crescendo significativamente nos últimos anos. Conforme dados da pesquisa "TIC Usuários e Domicílios - 2008", coordenada pelo Comitê Gestor da Internet no Brasil, 45\% das pessoas declararam que utilizam frequentemente centros pagos para acessar à Internet, sendo que os mesmos representam 35\% da amostra como o local mais frequente do acesso (como expusemos na tabela 1) É importante destacar também que a maioria dos frequentadores de lan houses é formada por jovens de baixa renda e com pouca escolaridade, um perfil muito aproximado daqueles que utilizam os telecentros.

Carvalho comenta sobre o crescimento das lan houses no Brasil:

(...) este crescimento da utilização das lan houses atualiza o debate sobre o papel do Estado e do mercado na disseminação das tecnologias. Aqui também encontramos posições extremas. De um lado, seguindo a linha das teorias críticas da comunicação, há os que negam as lan houses como espaço de inclusão digital, acreditando que só os telecentros públicos de acesso gratuito são efetivos, pois representam o uso "cidadão" das novas tecnologias de informação e comunicação. De outro lado, estão os entusiastas que decretam que, diante da ineficácia dos governos, são as lan houses que promovem a verdadeira inclusão digital no Brasil, uma vez que os telecentros existem em pouca quantidade e estão atrelados às políticas de governo e não às políticas de Estado (CARVALHO, 2009, p. 26).

Esse debate bastante acirrado demonstra o importante papel que esses centros pagos adquiriram, principalmente, nas comunidades de baixa renda. No presente trabalho, não se considera que as lan houses sejam vilãs do "programa de inclusão digital brasileiro"; pelo contrário, apresentam um importante papel em comunidades não providas de centros gratuitos. Contudo, as mesmas não são responsáveis por uma efetiva inclusão digital. Essa opção nada tem a ver com a pouca formalidade ou a falta da figura estatal, e, sim, pelo fato de a "inclusão" promovida pelas mesmas é mais limitada a sites de relacionamento, comunicação e 
entretenimento que, apesar de importantes, não representam grande parte das potencialidades que podem ser promovidas pela Internet.

\section{OS CENTROS PÚBLICOS DE ACESSO À INTERNET EM PORTO ALEGRE}

Nesta seção do trabalho, será exposto de modo mais aprofundado o contexto da inclusão digital e das transformações socioespaciais decorrentes dos centros públicos de Internet tomando como base o município de Porto Alegre, Primeiramente será apresentado um panorama geral sobre os telecentros e as lan houses do município. Posteriormente, dados e impressões coletados a partir da etapa de campo da presente pesquisa são analisados e sistematizados.

\subsection{OS TELECENTROS EM PORTO ALEGRE}

O programa de inclusão digital de Porto Alegre foi criado em 2001, durante a gestão do ex-prefeito Tarso Genro. No entanto, ainda em 2000, já surgiam os dois primeiros projetos de telecentros no município, quando as entidades SECIPAZ (Movimento Segurança, Cidadania e Paz) e CEA (Centro de Educação Ambiental) conjeturavam a criação de unidades no Parque Chico Mendes e na Vila Pinto, respectivamente. Entre as duas unidades iniciais, todavia, apenas o primeiro projeto acabou se concretizando ainda em 2001, sendo o mais antigo telecentro em funcionamento no município. A unidade da Vila Pinto só seria fundada posteriormente.

O conceito do projeto adotado inicialmente foi o seguinte:

Um telecentro é um espaço físico com equipamentos de informática que potencializa a democratização do espaço público, cultiva a solidariedade em todos os níveis, combate à exclusão social e o individualismo, prepara cidadãos e comunidades para melhorarem condições de vida e de trabalho (MACADAR \& REINHARD, 2002, p. 4, grifo nosso).

Analisando esse conceito, pode-se perceber o quanto ele se aproxima dos ideais básicos dos projetos de telecentros, tal como o combate à exclusão social através da inclusão digital e o aperfeiçoamento para a vida e o trabalho. Ao mesmo tempo, cabe destacar um termo utilizado neste conceito bastante caro à Geografia e 
a outras áreas do conhecimento preocupadas com o urbano: democratização do espaço. A noção de espaço público nos remete a praças, ruas, parques e demais aparatos de acesso público dentro do urbano, sendo de uso e posse comum. Ao possuir inerentemente esse termo, o conceito do projeto considera que os telecentros não apenas constituem um equipamento de uso coletivo, mas também concebe a Internet como um (ciber)espaço público, que deve ter acesso irrestrito à comunidade, sendo cada unidade um portal que permite que os indivíduos desfrutem dos benefícios proporcionados pelas TICs. Os telecentros de Porto Alegre, portanto, foram concebidos como um projeto de inclusão social que conseguisse beneficiar as comunidades nas quais estão inseridos, melhorando a qualidade de vida da população local.

Atualmente, o projeto de telecentros está vinculado à Secretaria Municipal de Direitos Humanos e Segurança Urbana (SMDHSU) de Porto Alegre, e conta com 38 unidades conveniadas com a Prefeitura Municipal (dados de junho de 2009). Essas unidades são geridas por associações comunitárias de bairro (representam a grande maioria dos telecentros), ONGs, sindicatos e fundações. É importante destacar que existem outros telecentros mantidos principalmente por escolas e pela iniciativa privada que não estão conveniados com a Prefeitura, o que significa que o universo de centros gratuitos de acesso à Internet é superior a essas 38 unidades.

\subsection{LAN HOUSES EM PORTO ALEGRE}

Conforme dados obtidos no site da Secretaria Municipal de Produção, Indústria e Comércio (SMIC) de Porto Alegre em março de 2010, existiam registrados no município 35 lan houses e 178 cybercafés. Tal como já fora exposto anteriormente, englobaremos essas duas categorias em apenas uma, sob o título de "centro de acesso pago à Internet", ou simplesmente "lan house".

Do total de 213 centros pagos de acesso à Internet oficialmente registrados em Porto Alegre, doze situam-se nos bairros Sarandi (correspondente à Região Norte), Rubem Berta e Passo das Pedras (correspondentes à Região Eixo Baltazar). Sob o ponto de vista das atividades mencionadas pela razão social, percebe-se que, tanto para aquelas registradas como lan houses, como para os cybercafés, há grande semelhança entre as discriminações oficiais. Os serviços oferecidos nesse 
tipo de estabelecimento, de maneira geral, não se limitam apenas ao acesso a computadores para uso na Internet ou jogos em rede. Em grande parte delas, há oferecimento de serviços de informática, fotocopiadora, sendo muito comum, também, a venda de artigos alimentícios, como refrigerantes, bolachas recheadas e salgadinhos empacotados.

Faz-se importante ressaltar que, embora apresentemos esses dados oficiais extraídos da secretaria responsável pela fiscalização e organização de estabelecimentos comerciais, há uma enorme quantidade de comércios desse tipo funcionando informalmente, sem qualquer tipo de alvará de funcionamento, portanto. Em nossas observações empíricas, porém, percebemos significativa semelhança entre os estabelecimentos "informais" e os "formais", inclusive quanto ao fornecimento dos serviços supracitados. Esses centros pagos acabam apresentando importante papel onde estão inseridos, constituindo um elo entre uma escala global (a própria Internet) e local (a comunidade usuária do estabelecimento).

\section{OS CENTROS PÚBLICOS DE ACESSO À INTERNET NA REALIDADE DA PERIFERIA DE PORTO ALEGRE}

Essa seção objetiva realizar um aprofundamento da conjuntura dos centros públicos de acesso à Internet no contexto da periferia de Porto Alegre. Dessa maneira, valorizaremos as impressões obtidas in loco, propondo uma relação com as temáticas abordadas no restante do trabalho. Essa reflexão se dá a partir da visita em telecentros e lan houses para a coleta de questionários e realização de entrevistas.

Em um primeiro momento, a ênfase é dada às lan houses; entre as visitadas, todas se situam em vias de movimento relativamente intenso no bairro Sarandi (que compõe a Zona Norte de Porto Alegre), apresentando uma média de usuários superior a 50 por dia. Por se tratar de estabelecimentos comerciais, procuramos preservar os nomes dos estabelecimentos. Portanto, os mesmos serão identificados simplesmente por "lan house A" e "lan house B".

A lan house A é um dos mais antigos empreendimentos deste tipo no bairro. O estabelecimento fora criado em 2003, tendo se instalado no atual endereço em 2006. Essa migração deveu-se à necessidade de imóveis que comportassem a 
ampliação do número de máquinas e de serviços que pudessem ser oferecidos, dado o crescimento da importância adquirida pelo local em questão, refletindo-se no aumento da quantidade de usuários. Atualmente, além de 20 computadores, o estabelecimento também fornece outros serviços vinculados à área de informática, como manutenção e conserto de equipamentos.

Constatou-se a importância da instalação do estabelecimento na época em que o mesmo foi criado, já que o fornecimento de acesso à rede mundial de computadores (em um período em que o computador era ainda menos acessível à população ${ }^{6}$ ) foi de suma importância para os usuários locais. Embora se tenha explanado anteriormente que o simples acesso às TICs não representa necessariamente a inclusão digital de um indivíduo ou grupo social, a criação de uma lan house nas imediações do bairro teve, no mínimo, um impacto positivo e de caráter espacial: a redução da distância ao centro público de acesso à Internet mais próximo, que ficava em um shopping center (o deslocamento de ônibus até o referido local leva mais de 40 minutos, sendo necessárias duas conduções). O estabelecimento fica aberto nos três turnos e apresenta maior movimentação à noite.

Na busca da realização de um perfil de usuários, pôde-se constatar que , os jovens da faixa etária entre 14 e 18 anos predominam no período da tarde, quando estão liberados das atividades escolares. Nos turnos da manhã e da noite, predominam pessoas entre 25 e 30 anos, que utilizam a lan house para acessar sua conta de e-mails e enviar currículos pela Internet, principalmente. Isso também é evidenciado pela ocupação dos usuários, compostos, em sua maioria, por estudantes e desempregados.

A lan house B, por sua vez, foi fundada em 2007 por um grupo de jovens empreendedores. De acordo com o levantamento realizado na SMIC, o referido estabelecimento não possui alvará de funcionamento, fato que o desonera dos diversos encargos e obrigações exigidos para a manutenção do documento - alvo de muitas reclamações e inclusive da falta de perspectiva de continuidade nesse ramo de negócio por parte do proprietário da lan house A. Essa questão da informalidade é algo recorrente no contexto destes estabelecimentos. Embora não

\footnotetext{
${ }^{6}$ Conforme dados apresentados por Pires (2005), com base em pesquisa do Internet World Stats, a porcentagem da população brasileira com acesso à Internet era de aproximadamente 10\% em 2004. A primeira unidade lançada pelo proprietário da lan house A ocorreu em 2003.
} 
tenhamos um levantamento detalhado em termos do quantitativo de unidades "não regulares", é nítida a existência dessa informalidade no tocante às lan houses da periferia.

Em termos de usos da Internet nos estabelecimentos visitados, destacam-se o envio e recebimento de e-mails, programas de comunicação instantânea (MSN e Windows Live Messenger), sites de relacionamento, portais de visualização e compartilhamento de vídeo (YouTube), Em um segundo plano, a realização de pesquisas para trabalhos de escola e faculdade apresenta relativa importância. Outra constatação importante é que $80 \%$ da amostra possui acesso a computadores em outros locais além da lan house, o que demonstra as múltiplas possibilidades de acesso à Internet para as populações que estão mais incluídas sob o ponto de vista da apropriação das TICs. A seguir, apresentamos um quadro-síntese elaborado a partir dos dados obtidos nos questionários:

\begin{tabular}{|c|c|}
\hline Sexo & Masculino (70\%) \\
\hline Idade & 21 anos (média) \\
\hline Tempo de permanência no local (por dia) & $\begin{array}{l}\text { Entre } 3 \text { e } 4 \text { horas (30\%); entre } 30 \text { minutos e } 1 \text { hora } \\
(20 \%)\end{array}$ \\
\hline Acesso à Internet em outros locais & $\operatorname{Sim}(80 \%)$, em casa $(60 \%)$ \\
\hline Escolaridade & Médio completo (30\%); Superior incompleto (20\%). \\
\hline Renda familiar & $\begin{array}{l}\text { De } 2 \text { a } 3 \text { salários mínimos (50\%); De } 1 \text { a } 2 \text { salários } \\
\text { mínimos }(37,5 \%)\end{array}$ \\
\hline Ocupação & Estudante $(37,5 \%)$ \\
\hline Usos mais frequentes* & $\begin{array}{l}\text { Sites de relacionamento ( } 77,8 \%) \text {, plataformas de } \\
\text { compartilhamento e visualização de vídeos } \\
(55,55 \%) \text {, sites de busca (44.44\%), E-mail } \\
(44,44 \%) \text {, software de comunicação instantânea } \\
(44,44 \%) \text {, jogos on line }(33,33 \%) \text {, }\end{array}$ \\
\hline
\end{tabular}

QUADRO 1- SÍNTESE DE DADOS SELECIONADOS ENTRE USUÁRIOS DE LAN

\section{HOUSES}

* Nesse caso, considera-se a porcentagem de usuários que assinalaram que faz o determinado uso diariamente ou quase todos os dias

Entre os telecentros, a primeira unidade visitada foi Telecentro Parque dos Maias, situado na Rua Saturnino Vanzelotti, na Cooperativa Habitacional do Parque dos Maias (Cooparque). A referida unidade foi criada em outubro de 2004 a partir de uma doação de computadores feita pela Refinaria Alberto Pasqualini, e encerrou suas atividades em setembro de 2009, durante a realização desta pesquisa, quando ocorreu um rompimento do convênio com a Prefeitura Municipal de Porto Alegre. 
O oferecimento de curso de informática consiste em um dos principais serviços oferecidos pelo telecentro; entretanto, apenas uma modalidade era ministrada, no caso, um curso básico de informática. Em termos de perfil de usuário, as camadas mais jovens utilizam a estrutura do local predominantemente para acessar a Internet, enquanto os mais velhos (principalmente a Terceira Idade) frequentam a unidade para participar do curso.

No período da pesquisa, o telecentro apresentava uma movimentação relativamente pequena, não ultrapassando 10 pessoas por turno, sendo essa amostra formada principalmente por estudantes e aposentados. A procedência dos mesmos é basicamente oriunda do próprio bairro, fato explicado pela sua própria localização, distante de grandes avenidas e pouco provida de linhas de ônibus. Além disso, próximos a essa unidade, há os telecentros Grande Santa Rosa e Nova Gleba, que atendem às comunidades homônimas respectivamente, ambas situadas dentro da Região Norte. A infra-estrutura do local, assim como a grande maioria dos telecentros, é bastante modesta, sendo inclusive alvo de críticas de usuários e monitores.

A segunda unidade visitada foi o Telecentro Vila Ingá, inaugurado em $1^{\circ}$ de julho de 2004, tendo como objetivo principal o oferecimento de cursos para a terceira idade. Essa faixa etária, tal como havíamos explicitado anteriormente, deve ser alvo das políticas públicas de inclusão digital, já que constitui um dos grupos com menor acessibilidade (apenas 3\% das pessoas com mais de 60 anos já acessaram a Internet pelo uma vez, conforme dados do Comitê Gestor da Internet no Brasil). Atualmente, esses cursos continuam sendo oferecidos, havendo aulas em três dias durante a semana. A unidade permanece aberta entre $8 \mathrm{~h}$ e $20 \mathrm{~h}$, mas a maior movimentação de usuários ocorre a partir das $18 \mathrm{~h}$, horário em que trabalhadores e alguns estudantes têm maior disponibilidade de tempo para frequentar o local.

A infra-estrutura do local também é bastante simples, contando com apenas 10 computadores e um quadro-branco utilizado como recurso didático para as aulas. Essa constatação consiste em um dos grandes problemas dos telecentros localizados no município: a falta ou precariedade de equipamentos que potencializem as possibilidades oferecidas pelas Tecnologias de Informação e Comunicação. Em uma pesquisa realizada por um dos autores deste trabalho no primeiro semestre de 2009 junto a monitores de alguns telecentros (MORAES, 
2009), constatou-se que a grande maioria das unidades não possui alguns equipamentos básicos, como impressora, scanner, caixas de som e gravadores de dados (CD e DVD). Sem sombra de dúvida, o acesso aos computadores e à Internet já se constitui em um primeiro passo para a inclusão digital; todavia, a inexistência de outros recursos e equipamentos constatada acaba incorrendo no que denominamos aqui de "inclusão digital precária" ou "acessibilidade precária", ou seja, há apenas o oferecimento do básico que um telecentro pode fornecer (computadores com Internet), sem um incremento de outras tecnologias que também compõem as TICs.

Ao contrário do que foi observado nas lan houses, há uma maior quantidade de pessoas que não possui computador em casa, fato que seguramente pode ser correlacionado com o nível de renda familiar, sensivelmente mais baixo. Constatouse que quatro pesquisados declararam ter renda familiar de até um salário mínimo (equivalente a $R \$ 465,00$ no período da pesquisa), faixa de renda que, embora com a redução de preços dos computadores, ainda se situa marginalizada sob o ponto de vista da inclusão digital (conforme dados do Comitê Gestor da Internet no Brasil, $83 \%$ das pessoas cuja renda familiar é igual ou inferior a um salário mínimo jamais acessou a Internet). Desse modo, o telecentro talvez represente a única possibilidade gratuita para o ingresso dessas pessoas no ciberespaço.

Os usos, porém, são bastante semelhantes aos de usuários de lan houses e não fogem do esperado para pessoas de faixas etárias mais jovens, como softwares de comunicação instantânea, sites de relacionamento (durante a pesquisa de campo, vários estavam utilizando o Orkut), e-mail e "buscadores" (sites para procura de informação), além de jogos (outro uso bastante comum durante a observação de campo). Ao mesmo tempo, faz-se importante destacar que muitos mencionaram que utilizam a Internet para buscar informações sobre emprego, o que significa que 0 telecentro cumpre pelo menos um papel que transcende o simples entretenimento. $A$ Internet contemporaneamente constitui-se em uma importante plataforma para envio de currículos, busca de informações sobre empregos, inscrição e estudo para concursos públicos. Além disso, conhecimentos em informática, mesmo que básicos, são fundamentais para quase todas as profissões e, inclusive, critério importante nos processos seletivos dos contratantes. 
A seguir, são apresentados alguns dados referentes ao perfil do usuário de telecentros, obtido a partir da análise dos questionários. A amostra é de 10 usuários.

\begin{tabular}{|l|l|}
\hline Sexo & Masculino (60\%) \\
\hline Idade & 17 anos (média) \\
\hline Tempo de permanência no local (por dia) & Entre 2 e 3 horas $(60 \%)$ \\
Sim $(90 \%)$, em casa $(60 \%)$, lan house $(60 \%)$
\end{tabular}

QUADRO 2 - SÍNTESE DE DADOS SELECIONADOS ENTRE USUÁRIOS DE TELECENTROS

* Nesse caso, considera-se a porcentagem de usuários que assinalaram que faz o determinado uso diariamente ou quase todos os dias

\section{CONSIDERAÇÕES E PROPOSIÇÕES FINAIS}

Ao longo deste artigo, o escopo central do estudo basicamente focou-se em algumas manifestações da emergência das TICs, mais especificamente os computadores e a Internet, em diferentes escalas, desde um panorama mais genérico e amplo até um estudo espacialmente pontual, representado aqui por uma análise de telecentros e lan houses em Porto Alegre, mais especificamente na periferia do município.

Os centros públicos de acesso à Internet apresentam especificidades inerentes ao seu âmbito de administração. Enquanto os telecentros, geridos pelo poder público, representam a possibilidade de acesso gratuito à Internet, as lan houses, um ramo comercial da iniciativa privada, oferecem um serviço de maneira paga. Mas surge daí uma instigante reflexão: será que efetivamente há uma espécie de dualidade entre estes dois tipos de centros públicos? Qual é a contribuição dos mesmos para a inclusão digital dos indivíduos que usufruem seus serviços? 0 processo de inclusão digital ocorre de fato?

Os dados obtidos na pesquisa demonstram que, embora haja diversidade em termos de perfil socioeconômico entre usuários de lan houses e telecentros, 
existem muitas semelhanças nos usos e na importância adquirida pela Internet para os mesmos. É importante ressaltar que, ao contrário de tempos pretéritos, quando o acesso a computadores e Internet era ainda mais dificultado e se dava normalmente em apenas um local (normalmente na residência ou no trabalho), pode-se dizer que há atualmente múltiplas possibilidades de locais de ingresso, como nos próprios centros públicos, em residência própria ou de parentes e amigos, no trabalho, na escola, entre outros. Foi possível constatar que, entre a maioria dos frequentadores de telecentros e lan houses pesquisados, o centro público representa apenas uma entre algumas possibilidades de local de acesso. Ao mesmo tempo, poucos frequentadores dos centros pagos conheciam algum telecentro, fato que certamente pode ser explicado pela inexistência de centros gratuitos próximos às lan houses visitadas durante a pesquisa de campo. Outra consideração importante a ser ressaltada é a construção de vínculos entre alguns usuários (principalmente os que permanecem por muito tempo nos estabelecimentos) com o local, principalmente o que foi observado nas lan houses, já que alguns frequentadores afirmaram que o principal motivo para ir ao centro pago de acesso à Internet é o encontro e o convívio com o grupo de amigos estabelecido no local.

Entretanto, ao ressaltar essa perspectiva de uma multiplicidade de locais de ingresso, não se deve criar a falsa expectativa de que as TICs estão universalizadas e que há um cenário de grande penetração dessas tecnologias em toda a sociedade. Ainda há uma série de barreiras impeditivas para o pleno acesso da população para o uso de computadores, principalmente aquelas relacionadas à inacessibilidade proporcionada pela falta de condições financeiras e pelo próprio desenvolvimento cognitivo concernente às habilidades e competências necessárias para o emprego das TICs. Nesse sentido, os telecentros apresentam um importante papel em termos de "educação digital", em função da possibilidade de realização de cursos, inclusive aqueles segmentados para algumas faixas etárias, como as oficinas de informática básica para jovens ou para idosos. No entanto, na maioria das unidades, os cursos restringem-se às noções básicas do funcionamento de um computador e de sistemas operacionais, que, sem sombra de dúvidas, são importantes, mas representam apenas uma entre muitas possibilidades oferecidas pelas TICs. O oferecimento de cursos aprofundados proporciona novas perspectivas para os usuários interessados; e esses conhecimentos são fundamentais para o uso 
da informática atualmente, sendo pré-requisito para a inserção no mercado de trabalho. Uma efetiva inclusão digital deriva também dessas iniciativas do poder público.

O alcance desses objetivos, contudo, se dará sobretudo com amplos investimentos no programa de inclusão digital do município, principalmente no treinamento de monitores, na melhoria da infra-estrutura física (a necessidade de reformas foi apontada como um dos grandes problemas na maioria dos telecentros) e de equipamentos (hardware e software), bem como na continuidade da criação de novas unidades de telecentros, principalmente em áreas do ainda não contempladas no município.

No contexto do acesso, os centros pagos apresentam papel representativo para aqueles que não dispõem de um computador na própria residência, tal como pôde ser evidenciado nos dados referentes ao local mais utilizado para acessar a Internet, que demonstram uma proporção semelhante ao acesso residencial. Contudo, seria incoerência afirmar que todos os indivíduos que usufruem esses serviços estão incluídos digitalmente. O acesso é apenas o primeiro degrau dentro desse complexo processo. A efetiva inclusão se dá a partir do momento em que o usuário consegue utilizar as potencialidades do emprego de computadores e da Internet de maneira ativa e crítica, julgando a procedência dos conteúdos aos quais tem acesso e utilizando essas ferramentas como uma ampliação da sua esfera de atuação na sociedade.

Os avanços relacionados à ampliação da população com acesso à Internet foram significativos nos últimos anos e demonstram uma alteração expressiva no cenário da inserção no ciberespaço. As TICs, atualmente, estão incorporadas ao cotidiano da sociedade, sendo quase impossível conceber, contemporaneamente, algumas atividades ou relações profissionais e sociais sem o auxílio dessas tecnologias. Mesmo assim, no Brasil, a maior parte da população jamais teve contato com um computador. Assim, o Estado ainda possui a tarefa de fomentar iniciativas que permitam uma maior universalização desses equipamentos, tanto em termos de acesso (nesse sentido, os telecentros são considerados um dos mais efetivos empreendimentos) quanto de posse (a compra em si). Portanto, a diminuição das tarifas para manutenção de uma linha telefônica (no caso do modem 
discado) e, principalmente, da banda larga representará um importante passo para uma melhoria qualitativa no tocante ao acesso a novas tecnologias.

Essa pesquisa demonstrou um panorama atual dos impactos das Tecnologias de Informação e Comunicação e como as mesmas alteram algumas dinâmicas espaciais, possuindo, como foco da análise, os centros públicos de acesso à Internet localizados na Região Norte de Porto Alegre. Esses centros, sejam eles gratuitos ou pagos, atendem principalmente às camadas da população que não possuem pleno ingresso ao uso de computadores. Ao mesmo tempo, foi possível constatar que os centros públicos representam apenas uma entre outras possibilidades de entrada, fato que evidencia uma maior facilidade de obter acesso à Internet atualmente, mesmo que a posse de um computador ainda esteja restrita a uma minoria da população brasileira. Este mesmo cenário, contudo, mostra-se extremamente efêmero, o que significa afirmar que a atual conjuntura poderá estar sensivelmente alterada dentro de 5 ou 10 anos, pois há a tendência de que o panorama da inclusão digital seja mais favorável nos próximos anos. Mantendo-se os níveis de crescimento verificados atualmente, uma maior parcela da população possuirá computador com acesso à Internet nos próximos anos, assim como se espera uma ampliação dos serviços disponíveis na rede, principalmente aqueles disponibilizados pelo poder público para uma ampliação da participação da população na gestão local, constituindo assim a chamada "democracia eletrônica". A velocidade das transformações sócio-espaciais decorrentes do advento das TICs é tão grande quanto à velocidade das informações proporcionada pela Internet, o que representa um contínuo e acelerado processo de metamorfose da própria Internet e da própria percepção dos usuários que nela "navegam" sobre os processos que ocorrem no ciberespaço (incluindo a própria compressão espaço-tempo), mas que também afetam o espaço geográfico. 


\section{REFERÊNCIAS}

AFONSO, Carlos A. Políticas Públicas e Inclusão Digital. In: COMITÊ GESTOR DA INTERNET NO BRASIL. Pesquisa sobre o uso das tecnologias da informação e da comunicação 2006. São Paulo, 2007, pp. 47-53.

ASSUMPÇÃO, Rodrigo Ortiz D’Avila. Além da Inclusão Digital: O Projeto sampa.org. 2001. 156 f. Dissertação (Mestrado em Ciências da Comunicação) Escola de Comunicações e Artes, Universidade de São Paulo, São Paulo, 2001.

CASTELLS, Manuel. A Galáxia da Internet: reflexões sobre a internet, os negócios e a sociedade. Rio de Janeiro: Jorge Zahar, 2003.

CARVALHO, Olívia Bandeira de Melo. Os "incluídos digitais" são "incluídos sociais"? Estado, mercado e a inserção dos indivíduos na sociedade da informação. Liinc em Revista, v.5, n.1, p. 19-31, mar. 2009. Disponível em: <http://www.ibict.br/liinc>. Acesso em 10 de julho de 2009

CHAPARRO, Jeffer. La segregación digital en contecto. Ar@cne. Revista electrónica de recursos en Internet sobre Geografía y Ciencias Sociales. Barcelona: Universidad de Barcelona, № 95, 10 de abril de 2007. Disponível em:<http://www.ub.es/geocrit/aracne/aracne-095.htm> Acesso em 9 de maio de 2009.

COMITÉ GESTOR DA INTERNET. Pesquisa sobre o Uso das Tecnologias da Informação e da Comunicação no Brasil: TIC Domicílios e TIC Empresas 2008. São Paulo: Comitê Gestor da Internet no Brasil, 2009. Disponível em $<$ http://www.cetic.br/tic/2008/index.htm>. Acesso em 19 de setembro de 2009.

LÉVY, Pierre. Cibercultura. São Paulo: Editora 34, 1999.

LUCAS, Clarinda Rodrigues. As tecnologias de informação e a exclusão digital. In: Revista Transinformação.Campinas, v. 14. 2002. Disponível em $<$ http://revistas.puc-campinas.edu.br/transinfo/viewissue.php?id=1>. Acesso em 9 de maio de 2009.

MACADAR, Marie Anne; REINHARD, Nicolau. Telecentros Comunitários Possibilitando a Inclusão Digital: um estudo de caso comparativo de iniciativas brasileiras. In: Encontro da Associação Nacional dos Programas de Pós-Graduação em Administração, 26., 2002., Salvador. Anais do 26을 ENANPAD. Salvador: ANPAD, 2002.

MAPA OFICIAL DIGITAL DE PORTO ALEGRE. Disponível em: <http://geo.procempa.com.br/geo/>. Acesso em 10 de junho de 2009.

MORAES, Fernando Dreissig de. Telecentros em Porto Alegre: usos, perfil de usuário e importância a partir da percepção dos monitores (Relatório de Pesquisa). 2009 
PIRES, Hindenburgo Francisco. A produção morfológica do ciberespaço e a apropriação dos fluxos informacionais no Brasil. Revista Scripta Nova -Revista Electrónica de Geografía y Ciencias Sociales. Barcelona: Universidad de Barcelona, 2005. Disponível em <http://www.ub.es/geocrit/sn/sn-194-19.htm> Acesso em 30 de outubro de 2009.

SANTOS, Milton. A Natureza do Espaço: técnica e tempo, razão e emoção. $4^{a}$ ed. São Paulo: Edusp, 2004.

SECRETARIA MUNICIPAL DE DIREITOS HUMANOS E SEGURANÇA URBANA DE PORTO ALEGRE. Sítio dos telecentros. Disponível em $<$ http://www2.portoalegre.rs.gov.br/smdhsu/default.php?p_secao=30>. Acesso em 9 de maio de 2009.

SECRETARIA MUNICIPAL DE PRODUÇÃO, INDÚSTRIA E COMÉRCIO DE PORTO ALEGRE. Sítio. Disponível em <www.portoalegre.rs.gov.br/smic >. Acesso em 9 de março de 2010.

SILVA, Carlos Alberto da; TANCMAN, Michele. A Dimensão Socioespacial do Ciberespaço: uma nota. GEOgraphia, Rio de Janeiro, ano 1, no 2, p. 55-66. 1999

SORJ, Bernardo. Brasil@povo.com: a luta contra a desigualdade na sociedade da informação. Rio de Janeiro: Jorge Zahar / Brasília: Unesco, 2003.

UEDA, Vanda. Accesar distintos territorios y disminuir la exclusión digital: el ejemplo de los telecentros en la ciudad de Porto Alegre. In: Congresso On Line do Observatório para a Cibersociedade, 2, 2 a 14 nov., 2004. Comunicações do II Congresso Online do Observatório para a Cibersociedade. OCS, 2004. Disponível em <http://www.cibersociedad.net/congres2004/index_pt.html >. Acesso em 9 de maio de 2009.

(Recebido em 12.03.2010. Aceito em 02.04.2011) 